\title{
LA VIVIENDA Y LOS JÓVENES: UNA EXPECTATIVA O UNA REALIDAD
}

\author{
Pilar García Almirall ${ }^{1}$ \\ Centro de Política de Suelo y Valoraciones \\ Universidad Politécnica de Cataluña
}

Remisión Artículo: 8-10-2007

Palabras Clave: Mercado residencial, urbanismo social, política de vivienda para jóvenes, Área de Barcelona, Cataluña

Resumen: En la ultima década, el espectacular crecimiento de los precios de la vivienda en España ha originado una situación critica frente al acceso a una vivienda de las personas mas jóvenes, inmigrantes, separadas, que afecta cada vez a un mayor grueso de población, en diversos trabajos se ha contextualizado y analizado el tema: Trilla, C. (2000), CES (2002), Miret, P. (2004), Trilla, C. (2004), OCJ (2005), García P., García A. Fullaondo, A. (2006). Esta corriente alcista, auspiciada por factores económicos, sociales y urbanos, obtiene su máxima expresión en las ciudades medias y grandes de nuestro país, afecta a los municipios colindantes y áreas metropolitanas, propiciando un encarecimiento de la vivienda en las principales urbes del Estado Español.

En este artículo se trata de enjuiciar lo ocurrido, en el caso de Cataluña y en particular en la Región Metropolitana de Barcelona, como referente de algunos factores clave en el ámbito económico y urbano, de las experiencias sociales, que han propiciado esta situación. En síntesis, una reflexión sobre algunas consideraciones necesarias para afrontar la denominada "crisis de la vivienda" cara a facilitar el acceso a la vivienda de los jóvenes.

\section{Introducción}

En el contexto europeo, la disposición de una vivienda digna adecuada a las necesidades de los hogares es un derecho de primera necesidad, reconocido en las respectivas constituciones (en España art 47) y la responsabilidad de garantizar ese derecho es de las autoridades públicas. La experiencia europea de la segunda mitad del siglo XX, se ha inspirado en principios diversos, unos liberales, otros más intervencionistas, para orientar una actuación que ha sido determinante del grado de satisfacción de ese derecho en cada país y etapa histórica, y que ha condicionado también sus posibilidades futuras de continuación. (Trilla C. 2001).

Esta actuación ha configurado diferentes realidades en la estructura residencial de cada país, en consonancia a su dinámica de población, y al amparo de distintos principios jurídicos: regulación urbanística, derecho de propiedad; mercados financieros; políticas fiscales; movimientos sociales; tipologías de mercado de vivienda, características y antigüedad del parque edificado. Con una clara determinación común, preservar del libre mercado una parte de la oferta residencial y diversificar las formas de acceso a la vivienda, mediante la articulación de instrumentos de seguimiento, control y ayuda dirigidos a los agentes involucrados (promotores, propietarios, arrendadores, inquilinos... ). Unas medidas que se han adaptado a las coyunturas y necesidades sociales cambiantes, asegurando una cobertura aceptable de las necesidades de vivienda, especialmente en Alemania occidental, Francia y Reino Unido.

\footnotetext{
${ }_{1}^{1}$ Persona de contacto Pilar García Almirall, correo: pilar.garcia-almirall@upc.edu

2 Trilla C. (2001); La política d'habitatge en una perspectiva europea comparada. Fundació "la Caixa", 2001.
} 
En la actualidad, las directrices de convergencia europea, sustentan que la disponibilidad, acceso y calidad de la vivienda debe seguir siendo una preocupación común en el conjunto de países de la unión, aun cuando su trayectoria histórica invalida cualquier iniciativa o propuesta de instrumentos comunes. El esfuerzo se centra en buscar el equilibrio entre las recientes tendencias a la flexibilización de medidas, desregulación, reducción de gasto público destinado al mantenimiento del parque de viviendas envejecidas, mayor orientación a la opción de propiedad, en algunos países, y otros con una realidad de mercado residencial unidireccional (solo de propiedad), donde se hace mas acusada la falta de recursos y alternativas para abastecer las nuevas demandas sociales.

En el sistema español se ha priorizado claramente el régimen de propiedad como fórmula de mayor cohesión social, de implicación en la conservación del parque edificado, y de estabilización de la población. Aun cuando hoy afloran sus limitantes, el exceso de concentración de estratos sociales homogéneos, sus dificultades de acometer los gastos de mantenimiento y conservación necesarios, el deterioro y degradación de algunos barrios ${ }^{3}$. Con todo es una vía aceptable, y refrendada por Europa, el conflicto surge en sus efectos económico-sociales que trascienden al mercado residencial, cuando constriñen toda posibilidad de acceso a la vivienda a un mercado de compra "casi en exclusiva", arraigado en tendencias liberalizadoras ${ }^{4}$, con importantes carencias estructurales, falto de transparencia y control.

En la trayectoria reciente, el avance excepcional del mercado residencial en España, ha superado todo pronóstico de reequilibrio racional, hacia un funcionamiento normalizado ${ }^{5}$, las grandes operaciones de vivienda alcanzan unos precios inaccesibles para un amplio sector social $^{6}$. Los excesos en la especulación en vivienda, han hecho saltar la alarma incluso en Naciones Unidas donde se recomienda "reflexionar seriamente sobre el funcionamiento del mercado, incluso interviniendo si es preciso para controlar la especulación sobre el suelo y la propiedad" con urgencia ${ }^{7}$.

\section{La vivienda, un bien escaso.}

La construcción residencial se ve influida por diversos factores, en especial por los derivados de los cambios poblacionales (formación de hogares, tipo, composición tamaño, movilidad residencial), a los niveles de renta y empleo (mejores expectativas, mayores dinámicas), de la disponibilidad financiera asequible, de la adecuación de los precios y costes de mantenimiento, del volumen de oferta (disponibilidad de producto vacante elegible), así como de la orientación de la demanda (conocimiento real del mercado). Además de su estrecha dependencia del clima económico, la dimensión temporal, la escala geográfica, que hacen de este un sector complejo y en muchos casos imprevisible.

La vivienda es un bien de primera necesidad, a la vez que es un bien "diferente" entendido como bien de consumo duradero, con un largo período de vida útil, que representa el "estatus

\footnotetext{
${ }^{3}$ Situaciones que han marcado en España diferentes políticas de actuación y regeneración de barrios, recientemente en Cataluña se perfila en la Ley de Barrios, entre otras ayudas a la rehabilitación.

${ }^{4}$ Roca J. Garcia P, Burns M. (2000) La liberalización del mercado de suelo en España. Reforma de la legislación urbanística 1998. European Planing Studies.

${ }^{5}$ En términos ideales, el equilibrio entre la oferta y la demanda de vivienda, asegura la proporcionalidad entre el valor de productos similares, evita excesivas alteraciones en cortos períodos de tiempo, y asegura la consistencia en el valor de los bienes.

${ }^{6}$ El encarecimiento de la vivienda, deja fuera de juego a los jóvenes "mileruistas", a las personas de clase media (divorciados, nuevos los núcleos de convivencia,...), los inmigrantes, a la gente mayor o con problemas de movilidad.

7 Ponce, Juli (2007) Lloguer social vs. Especulació. Jornada a la Universitat Progresista d'Estiu de Catalunya . http://www.universitatprogressista.org/documents/JPONCE14JULIOL07.ppt\#1
} 
social" o el estilo de vida de sus ocupantes. Así mismo, supone un activo para su propietario en la medida que la construcción de viviendas constituyen un porcentaje importante de la formación de capital fijo en todos países ${ }^{8}$, como recogen las estadísticas. De forma que la propiedad de vivienda puede identificarse en cierto modo, como bien de inversión, de acumulación de capital, de beneficios futuros, siempre y cuando su rendimiento supere los costes de acometerla ${ }^{9}$. En términos generales, la vivienda destinada a producir rentas genera rendimientos y cubre los riesgos económicos, costes de mantenimiento, mientras que la vivienda para uso propio constituye fundamentalmente un coste consumido por los hogares.

Los cambios sociales han transformado la tradicional visión de la vivienda como bien estable de larga duración, en un bien cambiante ajustado a las necesidades de cada etapa de la vida, movilidad y demás. Hecho que ha impulsado unas dinámicas activas en el sector residencial que ha favorecido ritmos de construcción y ventas crecientes $^{10}$, y el alza continuada de precios. En ese escenario, la vivienda aflora como una fuente aparente de capitalización rápida de beneficios (por los propietarios), fortalece sus expectativas de una inversión segura, situación que alienta un encarecimiento general del producto (recuperación de plusvalías), y acaba por desencadenar mayores dificultades de acceso a nuevos productos para todos, especialmente para los jóvenes o quienes no disponen de un ahorro o patrimonio inicial ${ }^{11}$.

Por otra parte, la vivienda es un producto heterogéneo, en cuanto a la localización, calidad y diseño, y a las diferencias económicas en función al tipo de producto ${ }^{12}$, y ubicación en una misma ciudad. Las restricciones del mercado de viviendas, que afecta a los diferentes submercados (venta: nueva construcción, usada semi nueva, antigua; alquiler: en sus diferentes estratos), se explican por la dificultad de lograr un equilibrio suficiente ofertademanda, dada la naturaleza de inamovible de la vivienda y los requerimientos de tiempo para ser construida.

La materialización de la vivienda exige: de una parte, la disposición de suelo (vacante o por regenerar) en ámbitos atractivos, de calidad arquitectónica, dotados de equipamientos y servicios, próximos a infraestructuras y centros de empleo; por otra un desembolso importante de dinero para acometer la edificación o rehabilitación de la estructura edificada. El suelo cualificado (en entornos urbanos consolidados) lleva implícito restricciones de oferta debidas a prácticas especulativas en estas áreas, como bien escaso susceptible de monopolio, de privatización de su rendimiento edificable.

Para hacer frente a las carencias del mercado y abastecer de vivienda a los segmentos mas vulnerables, los jóvenes entre otros, se requiere de una política que permita la materialización de vivienda asequible, eso implica, el abastecimiento de suelo cualificado y la financiación necesaria para acometer la edificación, rehabilitación como única vía para incidir en el mercado y atender las ineficiencias. Una actuación que trasciende al ámbito político, económico, legislativo y competencial de las distintas autoridades públicas, al desarrollo de medidas de alcance urbanística, fiscal, etc.

\footnotetext{
${ }^{8}$ Tradicionalmente con dinámicas totalmente distintas a la inversión en capital productivo fijo.

${ }^{9}$ Reseñar que, a parte del precio de compra, los gastos de adquisición superan el $10 \%$ del precio, los gastos anuales de mantenimiento, conservación y mejora según la antigüedad del edificio rondan el $2 \%$ de su valor, a parte de los gastos de reposición adecuación de la vivienda (baño, cocina, cerramientos, instalaciones, acabados...).

${ }^{10}$ La estabilidad económica de nuestro país, las facilidades en los créditos hipotecarios, la fiscalidad, el contexto económico internacional, entre otros factores, han decantado la demanda hacia la compra

${ }^{11}$ Toma así relevancia, entre el colectivo social, el valor patrimonial, de inversión o de cambio de la vivienda, frente al tradicional valor de uso y disfrute, causando una alarmante presión social de compra o inversión, sin evaluar todos los costes, riesgos económicos y alternativas, En una situación de toda vivienda es válida, sin considerar aspectos esenciales de su localización, calidad constructiva, habitabilidad............

${ }^{12}$ Arraigadas a sus prestaciones, tipología edificatoria, instalaciones y servicios comunes del edificio, calidad de sus materiales, acabados y demás, asumen unos costes diferenciados a lo largo de toda la vida útil del bien.
} 


\section{La protección de la vivienda en Cataluña}

La relevancia económica del sector de la vivienda, es un tema estudiado e identificado por algunos autores como la salvaguarda del crecimiento económico ${ }^{13}$, debido a su apreciación cuantitativa desde el punto de vista del valor añadido que genera. En los últimos años uno de los componentes impulsores del crecimiento en España es la construcción que acumula un alza del $40,3 \%$ (desde el 2000 ) y se sitúa en un 10,6\% del PIB, mientras que diez años antes sólo suponía el $6,55 \%$ del PIB ${ }^{14}$.

La actuación en vivienda en Europa surge con la revolución industrial, en España tiene un inicio tardío, en el siglo XX, cuando se desarrollan importantes medidas de intervención pública en la financiación, reducción de costes crediticios, regularización y estabilización del sector residencial, una actuación no siempre efectiva. Algunos expertos señalan, que la articulación de ciertas medidas de política económica, han tenido mayores efectos en la promoción de empleo que en solución del problema social de la vivienda.

Tras la primera tentativa de intervención social en materia de vivienda, la Ley de casas baratas (1911), es la ley de "viviendas protegidas" el 1939 que instaura el "Instituto Nacional de la Vivienda" (INV) la que afronta el importante déficit de parque de viviendas. Ente que impulso en Cataluña el Patronat Municipal de l'Habitatge (PMH) de Barcelona, que fue un agente relevante en la promoción de vivienda social. Las sucesivas legislaciones en la materia que se refunden en la ley de "Viviendas de Protección Oficial" el 1963, producen una activación del sector de la construcción de viviendas, incorporando al sector privado, con las "ayudas a la piedra" que aportan el acceso a la financiación, subvenciones directas al promotor y excepciones fiscales. Con ello, el parque de viviendas de Cataluña creció en mas de un millón (unos 3 millones en el conjunto d'España) entre 1961 y1976, con actuaciones algo caóticas y poco planificadas.

La etapa democrática, con importantes cambios estructurales, configura una crisis social y económica, y la caída de la producción y demanda residencia ${ }^{15}$. Algunas medidas buscan reactivar el sector, como la regularización del mercado hipotecario (1981), (VPO de protección privada), la nueva regulación de alquileres (1985 decreto Boyer).

La actuación decidida en política de vivienda de Cataluña, se concreta en el "Plan de Vivienda 1981-1983" y el Plan cuatrienal 1984-1987, que constituyen un impulso excepcional al sector (46\% de Vivienda Protegida sobre el total edificado del periodo), así como mejoras en parámetros de diseño y calidad, control de adjudicación y distribución territorial equilibrada de la vivienda de protección oficial. A finales del 1987 la reactivación del sector se hace patente, el nivel adquisitivo de la demanda se ve reforzado lo suficiente para afrontar el aumento de los precios de suelo y construcción.

Esta situación inflacionista, deja atrás la evolución del módulo de protección oficial, en especial el encarecimiento del suelo, hace inviable la promoción de VPO, que se reduce al $20 \%$ de la producción de vivienda (MOPU), y abandona las grandes ciudades.

El nuevo impulso en política de vivienda viene de la conjunción eficaz de las actuaciones estatales y autonómicas en la materia. Un convenio marco que impulsa un Plan de vivienda 1992-1995. Se amplían las actuaciones protegidas, se prevén fuertes ayudas económicas con subvenciones especificas para en acceso de los jóvenes a la vivienda, ayudas a la rehabilitación, a la urbanización de ciertos tipos de suelo, y se crean nuevas figuras de vivienda de precio tasado, entre otros. En esta etapa Cataluña recupera la oferta de Vivienda Protegida

\footnotetext{
${ }^{13}$ Blasco Torrejon B. (1993) Política de vivienda en España. Un análisis global Tesis doctoral inedita UCM Madrid

${ }^{14} \mathrm{Vega}$, José Antonio (2007). EI PIB supera el billón de euros. Cinco dias edicion impresa MADRID (29-08-2007)

${ }^{15}$ Incertidumbres económicas, reducción de migración y natalidad, caída del poder adquisitivo, aumento del paro, altos tipos de interés.
} 
que alcanza hasta el $40 \%$ de la oferta total con casi 30.000 viviendas a precio tasado y un total de más de 44.000 viviendas adquiridas por jóvenes ${ }^{16}$

El sector residencial se ve fortalecido por unas condiciones favorables del sector hipotecario, una fiscalidad orientada a la compra, un crecimiento económico, un déficit de vivienda en alquiler, unas medidas liberalizadoras en materia de suelo. Las consecuencias afectan directamente a un rápido encarecimiento del suelo, al crecimiento de sus expectativas de valor, que aumentan significativamente la proporción (del 25 hasta el $75 \%$ del valor de venta) en el precio de compra de vivienda.

Unas circunstancias que marcan el retroceso de Cataluña en cuanto a la actuación en Vivienda Protegida, que llega a situarse por debajo del 10\%, son evidentes las dificultades de actuación en vivienda por la elevada repercusión del suelo. Una tendencia que también experimentan las comunidades de Madrid, País Vasco o Navarra, comunidades que logran mayores dinámicas de Vivienda Protegida a partir del 2000, mientras que en Cataluña a partir del 2004

\section{La actuación en vivienda supera el marco disciplinar y competencial: hacia una acción coordinada}

Lo acontecido relata una falta de previsión en la actuación en materia de vivienda que ha dejado fuera de control al mercado inmobiliario. Se han olvidado los vínculos entre la actividad urbanística, los instrumentos de gestión y sus efectos en la creación de de patrimonios de suelo orientados a facilitar actuaciones de vivienda asequible, y ello no se ha puesto de manifiesto y se ha abordado con claridad hasta las recientes regulaciones en materia de urbanismo en Cataluña (2002 y 2004).

Una dificultad para abordar el fondo del problema es la diversidad de ámbitos competenciales y la multidisciplinariedad de las acciones que afectan a la materia. Mientras las competencias de actuación en materia de vivienda corresponden a las autonomías y entes locales, una parte de aspectos que configuran estas actuaciones son competencia del Estado. Se requiere de unas determinaciones coordinadas:

- La adopción de medidas que asuman el control del desarrollo urbanístico del suelo. La ley 8/2007 de suelo afronta los principios básicos de garantizar el medio ambiente, impedir la especulación y procurar el derecho a la vivienda digna y adecuada. Desarrolla una nueva regulación que afecta a la reserva de suelo para vivienda de protección pública. Dispone situaciones básicas de suelo rural y urbanizado, delimita sus expectativas de valor ${ }^{17}$. Determina los deberes de la promoción en las actuaciones de transformación urbanística. Dispone en la adicional novena, medidas anticorrupción que afectan la Ley 7/1985 Reguladora de las Bases de Régimen Local.

- El ámbito de los arrendamientos, demanda una modificación normativa que permita establecer un equilibrio adecuado en las prestaciones de las partes. Favorecer un cambio de cultura, requiere de una regulación mas precisa en cuanto a la protección del bien, el uso adecuado y la implicación en los costes de conservación, nuevas

16 MOTMA Ministerio de Fomento. Informe sobre la evolución del subsector de la vivienda. Seguimiento estadístico y financiero del Panel de Vivienda 1992-1996.

${ }^{17}$ Roca, J (2007) García-Bellido y La Renovación Del Paradigma Urbano: Post-Escriptum A La Propiedad Desagregada .Revista Ace. Número 3. Febrero 2007. 
consideraciones de permanencia o temporalidad, mayores incentivos y garantías. Un cambio necesario para potenciar la oferta en alquiler. Así como la activación de mercados alternativos de vivienda con la reserva de la titularidad pública del suelo ${ }^{18}$.

- Un ordenamiento adecuado de la política fiscal y financiera que atienda los diversos regimenes de tenencia o acceso a la vivienda, que no únicamente su adquisición. La propuesta de gravar determinadas acumulaciones de patrimonio residencial que no esté en uso. Asegurar el cumplimiento de la normativa de valoración de viviendas realizada por sociedades financieras o hipotecarias, que se refiera al valor consolidado, entre otros criterios afines a los fondos de inversiones inmobiliarios en Europa, de manera que estos constituyan una auténtica garantía del valor perdurable, con mínimos riesgos.

La actuación en materia de vivienda es competencia de alcance autonómico por lo que las directrices y decisiones dependen en gran medida de cada comunidad. Ello ha permitido que algunas autonomías por medio de regulaciones específicas, desarrollen un marco legislativo propio que, en algún caso, se anticipa al fuerte incremento de los precios de la vivienda y aporta instrumentos idóneos para generar una política de vivienda pública.

Un referente es el País Vasco, con el decreto de 1994 Ley $17 / 1994^{19}$ o la Comunidad de Madrid que en 1995 aprueba la Ley $9 / 1995^{20}$ en que la obligatoriedad de constituir patrimonios públicos de suelo ${ }^{21}$ permite anticipar-se i moderar en algunos ámbitos los fuertes incrementos del mercado residencial. Una actuación que en Cataluña no se produce hasta el 2002 con la Llei Catalana d'Urbanisme 2/2002, modificada el 2004 (Llei 10/2004) ${ }^{22}$, con un cierto retraso respecto a las comunidades mas avanzadas. La tendencia de realizar políticas sectoriales de vivienda, se ha visto limitada por la insuficiencia económica para abordar una actuación con la suficiente entidad para incidir en el mercado de vivienda. La promoción de vivienda pública o asequible exige la disposición de reservas de suelo, y que estas deban ser utilizadas para este fin, en el que debe contemplarse la producción de viviendas para jóvenes.

Hoy se han mejorado las condiciones necesarias en la actuación en materia de vivienda social. En el ámbito Estatal, un nuevo marco normativo más favorable, mayores partidas dirigidas a la financiación del sector, los mecanismos de coordinación en la acción de las distintas autoridades públicas (estado, autonomía, entes locales), constituyen pasos decisivos. En Cataluña, además del esfuerzo normativo en materia de urbanismo (antes citado), se ha desplegado una importante producción de regulación en materia de vivienda que va desde el Decreto 454/2004, que desarrolla el Pla pel Dret a l'Habitatge, y establece figuras intermedias de protección (precio concertado), el Decreto 455/2004 del Pla de Rehabilitació de Catalunya que articula medidas de control de la edificación (test del edificio), el nuevo Decreto 244/2005 refuerza el 454 y amplia con líneas de rehabilitación, y finalmente la tramitación en curso de la nueva llei de l'Habitatge de Catalunya, con importantes avances en el control del parque residencial y la adopción de líneas que garanticen ese derecho a los ciudadanos.

\footnotetext{
${ }^{18}$ Clavell, D. ; Trilla C. (2004) Propostes alternatives de promoció per a una nova orientació de l'oferta d'habitatge protegit de la Societat Urbanística Metropolitana de Rehabilitació i gestió, RS.A. REGESA

${ }_{19}$ Ley 17/1994 del País Vasco, de 30 junio, de medidas urgentes en materia de vivienda y tramitación de instrumentos de planeamiento y gestión urbanística.

${ }^{20}$ En la Comunidad de Madrid la Ley 9/1995 de 28 marzo, de medidas de política territorial, suelo y urbanismo.

${ }^{21}$ Se trata de reservar una parte proporcional de los terrenos que se transforman en urbanos con el planeamiento, en techo equivalente destinado a vivienda protegida, que es cedida al ente local, en una proporción del 20\% (o 30\%), 50\% o hasta el $65 \%$, para la construcción de vivienda asequible. Ello debe tener una traducción directa en la materialización de vivienda social.

${ }^{22}$ En Cataluña la Ley 10/2004 de 24 diciembre, que modifica la Ley 2/2002, de 14 de marzo, de urbanismo, para el fomento de la vivienda asequible, de la sostenibilidad territorial y la autonomía local.
} 
Con todo, las actuales directrices de actuación en materia de vivienda en Cataluña se afianzan en:

1. La necesidad de asegurar la financiación autonómica con capacidad de invertir en vivienda asequible.

2. Superar el conflicto competencial, cara a facilitar actuaciones mas afines al contexto geográfico y en especial a los ámbitos urbanos de gran centralidad.

3. Incentivar la promoción de viviendas en alquiler como déficit mas acusado.

4. La gestión y puesta en práctica de nuevas formas de régimen de tenencia, como la titularidad compartida, la vivienda en cesión de uso por medio de cooperativas. ${ }^{23}$

5. Reafirmar el papel capital de los municipios y entes locales en asegurar una actuación urbanística eficiente en la obtención de los patrimonios públicos de suelo imprescindibles para la actuación en Vivienda Protegida.

6. Introducir medidas reguladoras del mercado de suelo, capaces de reconducir el carácter liberalizador ${ }^{24}$, hacia sistemas basados en el autentico valor del suelo sin reconocer prematuras expectativas urbanísticas

7. Búsqueda de nuevas formas de producción de oferta más diversificada y asequible afín a las necesidades de la demanda, recuperar el interés de la promoción privada, en la medida que la demanda está garantizada.

En esta perspectiva el "plan de actuación en materia de vivienda" avanza ${ }^{25}$, con medidas que van desde ayudas a los promotores de Vivienda Protegida para incrementar la oferta especialmente de alquiler-, hasta ayudas para costear la vivienda a familias de bajos ingresos, o ayudas para la rehabilitación o incluso para ampliar las reservas de suelo destinadas la producción de Vivienda Protegida. Por otra parte, reconoce el papel decisivo de los ayuntamientos, e impulsa la participación de cooperativas y entidades sin ánimo de lucro para velar por el acceso a la vivienda de los colectivos más desfavorecidos.

\section{La vivienda y su componente espacial}

En la elección residencial, los jóvenes como otros ciudadanos buscan situarse en el lugar que les permita mantener unas buenas expectativas de trabajo, a la vez de una mejor calidad de vida, la disposición de infraestructuras (de movilidad y transporte) equipamientos culturales, comerciales, de ocio, recreativos, deportivos, entre otros atractivos. Aspectos que hacen referencia a la localización y la centralidad, la disposición de infraestructuras y servicios, así como de otros de cariz socio profesional.

El atractivo residencial de los diferentes lugares de Cataluña tienen una clara relación con componentes geográficos, relativos a la dimensión y la escalera urbana, metropolitana o regional, que perfilan una posición relativa al contexto económico, social, medioambiental y urbano para cada municipio. También a los aspectos relativos a la configuración urbana

\footnotetext{
${ }^{23}$ Modelos daneses ALMEN y ANDEL mediante cooperativas de cesión de uso. En Cataluña la organización sostre cívic ha gestionado la construcción de 40 viviendas en Cerdañola que se ocupan de acuerdo a ese regimen de cesión de uso siguiendo el modelo danes.

${ }^{24}$ Roca J. Garcia P, Burns M. (2000) op cit..

${ }^{25}$ Fernández, R. (2007) L'habitatge i la política d'habitatge a Catalunya. UPEC. Barcelona

http://www.universitatprogressista.org/documents/Habitatge\%20\%20Ricard\%20Fernandez.ppt\#1
} 
(densidad de edificación, espacios verdes) y al modelo de ciudad como factores de peso en el atractivo residencial.

En este sentido, diferentes autores se refieren al cambio en la producción de viviendas (en Barcelona provincia) dónde se han intensificado las tipologías de baja densidad ${ }^{26}$ especialmente entre 1980 y $1990^{27}$, en urbanización dispersa de alta intensidad de ocupación del suelo y vinculados a las infraestructuras viales. Crecimientos que únicamente se explican por la demanda de este tipo de vivienda, y que tienen un referente claro en la perspectiva de la formación espacial del mercado inmobiliario, como veremos seguidamente, pero que al fin presentan ciertos inconvenientes pues la difusión espacial de vivienda implica un elevado coste de mantenimiento de la vialidad, de las infraestructuras de transporte, de dependencia excesiva de transporte privado, de carencias en el terreno de equipamientos y servicios entre otros.

Algunas de las tendencias que se han producido en relación a la elección de la vivienda entre 1991- 2001 y hasta la actualidad pueden resumirse:

1. La descentralización de la residencia, ha significado un cambio importante en la población que ha afectado de forma mas acusada a los municipios medios y pequeños. Las familias se han desplazado de los municipios mas centrales, a otro mas periféricos con un precio de vivienda mes bajo. Esta tendencia supone una mejora en la relación calidad precio, aunque genera gastos importantes en tiempo y costes de desplazamientos, o de otras carencias en la búsqueda de servicios de proximidad.

2. Las mejoras en la accesibilidad, han permitido la extensión del ámbito de primera residencia especialmente en el entorno metropolitano de Barcelona, aportando más alternativas de elección.

3. La demanda proveniente de ámbitos mas caros, genera como consecuencia un incremento del precio de la vivienda, pues se equipara a los ámbitos centrales, lo que reduce la capacidad de acceso a una vivienda a los sectores menos solventes como los jóvenes. A la vez que se genera un efecto sobre el mercado de trabajo, pues se crea una nueva demanda de servicios en nuevos enclaves, que requiere alojar mas dotaciones, y de personal destinado a ellas.

4. Si bien, la absorción de altos crecimientos en vivienda (a menudo de baja densidad) en determinados municipios pequeños, comporta un grave déficit con respecto al mantenimiento de las infraestructuras o la falta de dotaciones y servicios (comercio de proximidad, centros de asistencia primaria, escuelas, actividades complementarias en la escuela, actividades deportivas, culturales, instalaciones polideportivas). A pesar de los grandes esfuerzos de los ayuntamientos, en algunos casos los municipios no disponen de un núcleo urbano lo bastante amplio y preparado para alojar estas nuevas necesidades, lo que supone ciertos inconvenientes para sus habitantes.

5. Por otro lado, la descentralización y reestructuración de los sectores económicos significa para muchos municipios de tamaño medio o grande, un reforzamiento de la actividad y un cambio hacia su terciarización, hecho que se traduce en un aumento de puestos de trabajo en los municipios centrales con un alto nivel de extensión del sector servicios, una oferta de trabajo cualificado.

\footnotetext{
${ }^{26}$ Muñoz, F (2004) Urbanalització. La producció residencial de baixa densitat a la provincia de Barcelona, 1985-2001. Tesi Doctoral UAB. http://www.ub.es/geocrit/b3w-528.htm

${ }^{27}$ Capel H (2005) El modelo Barcelona: Un examen crítico, ediciones de Serbal. Barcelona. pag 39 cita Muñoz (2004); Monclús (1998); Nel·lo (2001).
} 
En definitiva, las nuevas actuaciones de vivienda han jugado un papel diferenciado en relación al perfil de ciudad (morfológico), su estructura económica y social. En los ámbitos de mayor centralidad (grandes ciudades y algunos municipios del ámbito metropolitano), las promociones de vivienda han servido para reforzar la centralidad y el crecimiento económico. En las ciudades medias o pequeñas han tendido a expandir se en actuaciones dispersas mas que a la consolidación de sus núcleos compactos, alcanzando un papel poco estructurador en algunos casos. En el ámbito rural las actuaciones tienen una casuística mas diversificada de orientación en segunda residencia, turismo rural y otros que en algunos casos si que refuerzan la actividad económica pero en otros generan cierta segregación social.

\section{La conformación de un espacio residencial: la Región Metropolitana de Barcelona}

Estas tendencias en la elección residencial han orientado los procesos de movilidad residencial en la Región Metropolitana de Barcelona (RMB) ${ }^{28}$, y han favorecido la intensificación de una estructura poli nuclear ${ }^{29}$ de una parte, y la expansión del urbanismo disperso. Un espacio donde arraigan las nuevas dinámicas sociales, que conforman un nuevo orden geográfico y funcional, una transformación que se plasma en la formación del mercado residencial.

La RMB es un ámbito con un total de 164 municipios, que sobrepasan los 4,8 millones de habitantes en enero del 2006, con diversidad de tamaños de población. El crecimiento reciente (1991-2001) del conjunto de la Región, responde a un incremento de población de tan solo el $3 \%$, frente a un $17 \%$ de los hogares y un $19 \%$ de las viviendas, mientras el análisis por rangos de población, pone en evidencia el crecimiento mas acusado de los municipios medios o pequeños, además de una mayor relevancia del incremento de hogares que el de las viviendas en esos municipios ${ }^{30}$. Ello se explica, por el hecho de que en los municipios más pequeños con un elevado crecimiento, se maximiza la conversión de segundas residencias en principales, aunque este fenómeno se produce en todos los rangos de tamaño municipal.

La trayectoria reciente ha conformado este espacio residencial centrado en una ciudad como Barcelona de alto atractivo, con un área central conurbana de alta densidad y por un sistema de polaridades de ciudades medias que diversifican su estructura territorial. Se caracteriza por una amplia diversidad de producto edificado, que ha facilitado el tránsito de una población, con una dinámica excepcional ${ }^{31}$, pues parece ser que más del $50 \%$ de las viviendas principales han sido ocupadas en el periodo entre 1991-2001.

Para comprender lo ocurrido, hay que referenciar algunos de los factores que han perfilado la situación actual, citar una cronología de acontecimientos que han auspiciado uno de los ciclos alcistas mas prolongado, y que ha tenido un impacto acusado en el mercado residencial de la RMB.

1. El despegue de la "segunda residencia" (en los 60-70)". De una parte, la proliferación de urbanizaciones irregulares en ámbitos abruptos y poco accesibles, de otra las promociones de "chales" de montaña y apartamentos de playa, dan acceso a un

\footnotetext{
${ }^{28}$ Pujadas, I (2005) Movilidad Residencial y dispersión urbana: ¿mito o realidad? La movilidad residencial en la Región Metropolitana de Barcelona, 1982-2000 XXXI REUNIÓN ESTUDIOS REGIONALES, Alcalá de Henares, 17-18 de noviembre de 2.005 (edición digital ISBN 84-689-3845-9)

${ }^{29}$ Font, A. (2004): L'explosió de la ciutat. Morfologies, mirades i mocions sobre les transformacions territorials recents en les regions urbanes de l'Europa Meridional, Barcelona: Col.legi d'Arquitectes de Catalunya i Fòrum Universal de les Cultures.

${ }^{30}$ Los municipios de menos de 10.000 habitantes han crecido en población por encima del $45 \%$ en hogares el $65 \%$ y en vivienda el $30 \%$.

${ }^{31}$ Según datos del censo 2001 del total de mas de 1,6 millones de viviendas principales en la RMB, en mas del 50\% declaran sus moradores haber accedido a ella entre 1991-2001.
} 
terreno o vivienda con escasos servicios a muchas familias que harán un uso estacional de esa segunda residencia.

2. En los ' 70 , la propiedad toma el relevo al alquiler (53,3\%, 46,7\%), en Cataluña, también en España. La vivienda de compra es una opción muy extendida en la conurbación de Barcelona, en polígonos residenciales, en la renovación de los centros urbanos y en los enclaves turísticos (costa y montaña). Las restricciones de unas rentas indefinidas, restan atractivo ( $y$ rentabilidad) al alquiler, con dificultades de mantenimiento y renovación de los edificios.

3. Un revulsivo al alquiler que potenció la venta. La Ley Boyer (1985), y la ley de arrendamientos (1994), abren vías a la actualización de rentas, limitan la temporalidad, con el fin de recuperar el interés por el arrendamiento. Ello libera stock envejecido en alquiler, pero la falta de liquidez exige la venta de los patrimonios en alquiler privados, de bancos y cajas, o el parque social. Así de una parte, unos inquilinos se convirtieron en propietarios de una vivienda envejecida pero barata, mientras otros veían con incertidumbre como se debilitaba la estabilidad en el alquiler.

4. Una la política macroeconómica (fiscal) del Gobierno del Estado que beneficia la vivienda de compra. Frente a las dificultades de financiación y los elevados costes de rehabilitación o adecuación de viviendas envejecidas a los nuevos estándares, que frenan la inversión en alquiler.

5. El cambio de escala de Barcelona en el mapa mundial, se produce en 1986 cuando Barcelona se convierta en referente olímpico, en el contexto de la CEE. Su impacto se traduce en un alza en el mercado residencial

6. La descentralización de Barcelona y su conurbación, se extiende y amplia. La búsqueda de vivienda adecuada a sus necesidades, y de mejor calidad de vida y ambiental, son los argumentos mas esgrimidos. Los jóvenes (<34 años) representan tres cuartas partes (65\%) de los que se marchan de BCN el $87-88$ y se quedan en la provincia y el 39\% tienen entre 29 y 34 años, la mayoría trabajan en Barcelona ${ }^{32}$.

7. La nueva dimensión del mercado residencial amplia el ámbito de $1^{\text {a }}$ residencia incorpora zonas periféricas, o de urbanización irregular. Coincide con una estabilidad de precios (1991-1997), una alta dinámica de actuaciones protegidas (tasadas) que poco a poco deben retirarse de las zonas centrales.

8. En los noventa la bajada los tipos de interés, mejora la solvencia económica de las familias, la competencia fomenta nuevos productos hipotecarios. Los bancos y cajas se ajustan a las exigencias de los clientes (una garantía en alza, un alto porcentaje de préstamo, acomodación de cuotas) superando el nivel de riesgos aceptables, en algunos casos.

9. A finales de los noventa se consolida una mayor demanda, con una mayor disponibilidad de pago, muy orientada a una de mejora de calidad de la vivienda, o a la $2^{\mathrm{a}}$ residencia, o bien de inversión de cara a futuro y se produce un nuevo salto en los precios.

\footnotetext{
${ }^{32}$ Garcia, P. y Renau A. (1991) La emigración de Barcelona: causas y características. El mercado de la vivienda como factor incentivador de la emigración. 1991.UPC
} 
10. La revalorización ${ }^{33}$, afecta al conjunto metropolitano, consolida excepcionales plusvalías en la primera corona ${ }^{34}$, refuerza las expectativas alcistas, que alientan la movilidad residencial. La nueva construcción incrementa su actividad que entre 19962006 se ve duplicada (de 50.000 a 120.000 ), sin un impacto apreciable sobre la necesidad social de vivienda, y si sobre la destrucción de ámbitos naturales o de interés paisajístico.

Se llega así a una situación de extrema dificultad en el acceso a la vivienda, que afecta directamente a la población joven o en edad de emanciparse, entre otros colectivos, y que se ha visto agravada hasta límites para todos imprevisibles en los últimos años.

\section{El acceso a la vivienda realidad o expectativa}

El problema de la vivienda trasciende del interés propio, individual, para implicar al grueso colectivo de jóvenes ${ }^{35}$. La ciudadanía, se hace consciente de la envergadura del tema, se organiza en colectivos para exigir alternativas que frenen los excesos en la especulación inmobiliaria, que se den salidas realistas. Diferentes plataformas protagonizan, acciones sociales de movilización en torno al acceso a la vivienda y en defensa de este derecho constitucional, con un importante seguimiento y repercusión mediática, que recalan en la conciencia política y social sobre la problemática.

Comienza a fraguarse un cambio cultural, que no solo arrastra a los mas jóvenes sino también a movimientos sociales en defensa del territorio y del paisaje, que exigen a las autoridades públicas un mayor control sobre la actuación en el territorio, que se articulen medidas y se ejerciten en el cumplimiento de las mismas, encaminadas a asegurar un uso racional del territorio y de las viviendas. Hoy existe una regulación que ampara una extensa capacidad de actuación de las administraciones públicas en ese sentido, que además cuenta con un amplio respaldo social.

Las referencias a Francia son un ejemplo de la imposición de la obligación a los municipios de cierto tamaño de llegar a tener en el plazo de 20 años un $20 \%$ de sus viviendas en alquiler social. Frente a otras técnicas presentes en el mundo anglosajón inclusionary zoning, affordable, housing obligations y planning obligations en Estados Unidos, Canadá y Reino Unido respectivamente que imponen la obligación a los developers (promotores) de construir un determinado porcentaje de vivienda de precio accesible, generalmente en alquiler ${ }^{36}$. Unas experiencias que han servido para impulsar las necesarias reservas de suelo para Vivienda Protegida de la Ley 17/1994 de la Comunidad Autónoma del País Vasco, entre otros instrumentos con importantes efectos prácticos de control del mercado de la vivienda.

Toma de nuevo protagonismo el concepto del urbanismo como función pública, que ha de garantizar el cumplimiento de la función social de la propiedad. Los nuevos instrumentos normativos, tanto la Ley Estatal de Suelo, como proyecto de Ley por el Derecho a la Vivienda de Cataluña, tienen por objeto fomentar la transparencia y la participación ciudadana, así como el desarrollo urbano sostenible y garantizar la creación de un parque público de viviendas,

\footnotetext{
${ }^{33}$ Marmolejo C. Roca.J. y otros (2005) Informe sobre el mercado inmobiliario de Barcelona y su área metropolitana. Una visión retrospectiva y prospectiva. CPSV. UPC Barcelona.

${ }^{34}$ Como señala Marmolejo (2005) op.cit. Entre 1991 al 2004, la divergencia entre el crecimiento de los valores residenciales se atenúa, dado el diferente signo de los crecimientos entre ambos periodos. En estos 14 años la ciudad central se ha revalorizado en un $162 \%$, el resto de municipios del Plan Estratégico $265 \%$ y finalmente el resto de municipios de la RMB, es decir, la segunda corona en $226 \%$.

${ }^{35}$ Alabart, A. Gavaldà, J. Vilà G. (2006) Els joves i l'habitatge demandes, okupació i habitatge alternatiu. IX Setmana d'Estudis Urbans de Lleida. Lleida. España.http://www.geosoc.udl.es/SEU/presentacions/presentacio Alabart.pdf

${ }^{36}$ Burón Cuadrado J. (2006) Las reservas de suelo para vivienda protegida: lecciones del caso de Vitoria-Gasteiz. Revista ACE. № 2. Barcelona
} 
rescatando las plusvalías urbanísticas en favor de la comunidad y dirigido, expresamente, a los patrimonios públicos de suelo.

El actual contexto económico, la ralentización al sector residencial, puede ser una oportunidad inaplazable para reconducir la actuación en vivienda hacia un nuevo escenario. Los poderes públicos, junto con los demás agentes actuantes en el sector inmobiliario comienzan a implicarse en la resolución de los problemas de vivienda de la población, cara a ofrecer viviendas a precio asequible a la ciudadanía, viviendas cuya obtención no obligue a un endeudamiento permanente y desproporcionado.

Es el momento de poner en práctica una actuación decidida en política social y de vivienda, una actuación que hoy se articula entorno al Pacto Nacional Por la Vivienda en Cataluña ${ }^{37}$ que conmina una actuación concertada de los agentes actuantes en el sector residencial, en una dirección clara que en el que se destacan los siguientes metas:

1. Mejorar el acceso a la vivienda, especialmente de los jóvenes, mediante la provisión de un volumen de vivienda accesible suficiente y de ayudas en el pago del alojamiento.

2. Mejorar las condiciones del parque de viviendas, mediante el fomento del mantenimiento y la rehabilitación de los edificios.

3. Mejorar el alojamiento de la gente mayor y de las personas con discapacidad, mediante medidas de accesibilidad y de soporte económico.

4. Prevenir la exclusión social residencial, mediante un sistema universal de ayudas personales en el pago de la vivienda, y la dotación suficiente de viviendas de inclusión.

5. Garantizar un alojamiento digno y adecuado a los hogares mal alojados, mediante la erradicación del fenómeno del sin techo, la sobre-ocupación de las viviendas y la infravivienda.

Un pacto que puede tener una incidencia crucial en mejorar el acceso a la vivienda de los jóvenes, haciendo realidad la creación de oferta de vivienda accesible, en la medida que se consiga actuar con rapidez para hacer aflorar suelo disponible, conocer cuanto y donde se encuentra ese suelo, ubicar los ámbitos de mayor demanda potencial de viviendas, facilitar la actuación (urbanización y promoción de viviendas), asegurar la buena sincronización de la acción concertada con administraciones locales, instituciones públicas, y demás agentes. En síntesis una actuación dinámica que resuelva las actuales carencias.

\section{Comentarios finales}

La materialización de un grueso importante de viviendas accesibles a los jóvenes, es el primer paso para la creación de una verdadera alternativa al mercado libre de viviendas, un parque que asuma y perdure en su función social, que permita atender las necesidades de las diferentes demandas - de los jóvenes entre otras- que se ajuste a unas opciones de vida mas flexibles, que no transitorias.

Es preciso trazar nuevos imaginarios de acceso a la vivienda para los jóvenes, hacer efectiva mayores ofertas y mas diversas que respalden una vía de acceso a la vivienda aceptable, en la que el alquiler $u$ otras formas de acceso se perciban como flexibles y acordes con las necesidades de estabilidad de cada hogar. Una activación de nueva oferta tal vez haga retornar la confianza en el alquiler como modo de vida.

\footnotetext{
${ }^{37}$ Secretaria d'habitatge (2007) Pacte Nacional per l'Habitatge 2007-2016 http://mediambient.gencat.net/cat/ciutadans/habitatge/pacte habitatge 2007.pdf
} 
Algunas experiencias como la de Vitoria-Gasteiz, dan cuenta de cómo una política de control municipal del suelo y fomento de la promoción de Vivienda Protegida ha tenido, al sostenerse en el tiempo y seguirla las sucesivas administraciones, efectos configuradores sobre la personalidad urbana y social de la ciudad.

Consolidar dinámicas alternativas de acceso a la vivienda requiere que las autoridades públicas dispongan de un parque residencial suficiente, ejerciendo una buena gestión de la vivienda social, asegurando el control de la transmisión de la Vivienda Protegida. Por otra parte una actuación diligente frente al control de la especulación en suelo o en vivienda.

La creación de oferta residencial precisa de materia prima: suelo vacante o edificado a regenerar, y financiación para ejecutarlo. También de una ubicación en un lugar atractivo, próximo a las áreas centrales o de buena accesibilidad. Las reservas de suelo para vivienda son el elemento clave para hacer efectiva la nueva oferta, los efectos de las reservas de suelo para Vivienda Protegida tiende a limitar la rapidez y los precios de las ventas de Vivienda Libre.

En síntesi, cabe recuperar los vínculos entre la actividad urbanística, los instrumentos de gestión y sus efectos sobre los derechos reconocidos a la propiedad privada. Una propiedad privada en la que su función social debe ser mucho más presente o explícita tanto en el ámbito social como en el urbano.

\section{Bibliografia}

Alabart, A. Gavaldà, J. Vilà G. (2006) Els joves i l'habitatge demandes, okupació i habitatge alternatiu. IX Setmana d'Estudis Urbans de Lleida. Lleida. España.http://www.geosoc.udl.es/SEU/presentacions/presentacio Alabart.pdf

Blasco Torrejon B. (1993) Política de vivienda en España. Un análisis global Tesis doctoral inedita UCM Madrid

Burón Cuadrado J. (2006) Las reservas de suelo para vivienda protegida: lecciones del caso de Vitoria-Gasteiz. Revista ACE. NN 2 . Barcelona

Capel H (2005) El modelo Barcelona: Un examen crítico, ediciones de Serbal. Barcelona. pag 39 cita Muñoz (2004); Monclús (1998); Nel·lo (2001).

CES (2002) La emancipación de los jóvenes y la situación de la vivienda en España

Clavell, D. ; Trilla C. (2004) Propostes alternatives de promoció per a una nova orientació de l'oferta d'habitatge protegit de la Societat Urbanística Metropolitana de Rehabilitació i gestió, RS.A. REGESA

Fernández, R. (2007) L'habitatge i la política d'habitatge a Catalunya. UPEC. Barcelona http://www.universitatprogressista.org/documents/Habitatge\%20\%20Ricard\%20Fernandez.ppt\#1

Font, A. (2004): L'explosió de la ciutat. Morfologies, mirades i mocions sobre les transformacions territorials recents en les regions urbanes de l'Europa Meridional, Barcelona: Col.legi d'Arquitectes de Catalunya i Fòrum Universal de les Cultures. 
Garcia, P. y Renau A. (1991) La emigración de Barcelona: causas y características. El mercado de la vivienda como factor incentivador de la emigración. 1991.UPC

Garcia P. Garcia A. Fullaondo A. (2006) La problemàtica de l'habitatge dels joves a Catalunya . CPSV. UPC. Barcelona.

Mancomunitat de Municipis de L'àrea Metropolitana de Barcelona (2003), El Territori Metropolità de Barcelona: Dades Bàsiques, Evolució Recent i Perspectives. Barcelona.

Marmolejo C. Roca.J. y otros (2005) Informe sobre el mercado inmobiliario de Barcelona y su área metropolitana. Una visión retrospectiva y prospectiva. CPSV. UPC Barcelona.

Miret, P. (2004) Emancipació domiciliària, laboral i familiar dels joves de Catalunya Col-lecció aportacions 25, Barcelona, Secretaria General de la Joventut.

MOTMA (1997) Ministerio de Fomento. Informe sobre la evolución del subsector de la vivienda. Seguimiento estadístico y financiero del Panel de Vivienda 1992-1996.

Muñoz, F (2004) Urbanalització. La producció residencial de baixa densitat a la provincia de Barcelona, 1985-2001. Tesi Doctoral UAB. http://www.ub.es/geocrit/b3w-528.htm

Observatori Català de la Joventut (2005): Informe sobre la joventut al 2005. Col.lecció Estudis, $n^{0} 17$. Observatori Català de la Joventut. Secretaria General de Joventut

Ponce, Juli (2007) Lloguer social vs. Especulació. Jornada a la Universitat Progresista d'Estiu de Catalunya . http://www.universitatprogressista.org/documents/JPONCE14JULIOL07.ppt\#1 Pujadas, I (2005) Movilidad Residencial y dispersión urbana: ¿mito o realidad? La movilidad residencial en la Región Metropolitana de Barcelona, 1982-2000 XXXI REUNIÓN ESTUDIOS REGIONALES, Alcalá de Henares, 17-18 de noviembre de 2.005 (edición digital ISBN 84689-3845-9)

Roca J. Garcia P, Burns M. (2000) La liberalización del mercado de suelo en España. Reforma de la legislación urbanística 1998. European Planing Studies.

Roca Cladera, J. Clusa. J. Mur, S. (2003). El Mercat Inmobiliari de La Regió Metropolitana de Barcelona i les comarques centrals de Catalunya. Centre de Política de Sòl i Valoracions I Universitat Politécnica de Catalunya, Barcelona

Roca, J (2007) García-Bellido y La Renovación Del Paradigma Urbano: Post-Escriptum A La Propiedad Desagregada .Revista Ace. Número 3. Febrero 2007.

Secretaria d'habitatge (2007) Pacte Nacional per l'Habitatge 2007-2016 http://mediambient.gencat.net/cat/ciutadans/habitatge/pacte habitatge 2007.pdf

Trilla C. (2001); La política d'habitatge en una perspectiva europea comparada. Fundació "la Caixa", 2001

Trilla, C.; DEP Consultoria Estratègica (2004) Els joves catalans i l'habitatge 1999-2003 col.lecció estudis 12, Barcelona, Secretaria General de la Joventut. 
Trilla, C.; Institut DEP (2000) Els joves catalans i l'habitatge col-lecció estudis 3, Barcelona, Secretaria General de la Joventut.

Vega, José Antonio (2007). El PIB supera el billón de euros. Cinco dias edicion impresa MADRID (29-08-2007) 
Architecture, City, and Environment

Arquitectura, Ciudad y Entorno 